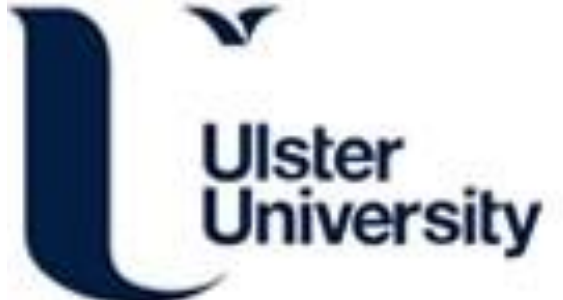

\section{Techno-Economic Analysis of Thermal Power Generation in a System with High Levels of Non-dispatchable Renewable Energy}

Keatley, P., \& Hewitt, N. (2008). Techno-Economic Analysis of Thermal Power Generation in a System with High Levels of Non-dispatchable Renewable Energy. In Proceedings of the 43rd International Universities Power Engineering Conference, 2008. UPEC 2008. (Vol. 1, pp. 1-5). IEEE.

https://doi.org/10.1109/UPEC.2008.4651573

Link to publication record in Ulster University Research Portal

Published in:

Proceedings of the 43rd International Universities Power Engineering Conference, 2008. UPEC 2008.

Publication Status:

Published (in print/issue): 04/09/2008

DOI:

10.1109/UPEC.2008.4651573

Document Version

Publisher's PDF, also known as Version of record

\section{General rights}

Copyright for the publications made accessible via Ulster University's Research Portal is retained by the author(s) and / or other copyright owners and it is a condition of accessing these publications that users recognise and abide by the legal requirements associated with these rights.

\section{Take down policy}

The Research Portal is Ulster University's institutional repository that provides access to Ulster's research outputs. Every effort has been made to ensure that content in the Research Portal does not infringe any person's rights, or applicable UK laws. If you discover content in the Research Portal that you believe breaches copyright or violates any law, please contact pure-support@ulster.ac.uk. 


\section{Techno-Economic Analysis of Thermal Power Generation in a System with High Levels of Non-dispatchable Renewable Energy}

\author{
Patrick Keatley \\ University of Ulster \\ keatley-p@ulster.ac.uk
}

\author{
Neil Hewitt \\ University of Ulster \\ nj.hewitt@ulster.ac.uk
}

\begin{abstract}
Cyclic operation of base thermal plant in the recently liberalized Irish all-island electricity market is set to increase with the expansion of variable renewable (principally wind) generation. This paper examines the effects of this change of operational regime for existing conventional generation plant.
\end{abstract}

\section{INTRODUCTION}

Historically the Irish electricity network was divided into two separately designed and constructed systems, one in each jurisdiction (Northern Ireland and the Republic of Ireland), both of which were operated as vertically integrated, centralized utilities. The systems were physically linked in 2001 by two $275 \mathrm{kV}$ parallel circuits and two $110 \mathrm{kV}$ lines, and since $1^{\text {st }}$ November 2007 have been operating as a single gross pool market (the Single Electricity Market or SEM) [1]. A further $400 \mathrm{kV}$ North-South interconnector is expected to be operational by 2012. External to the island, a 500MW interconnector links the Irish system with Britain, and another similar HVDC link is planned for 2012 [2,3]. Situated on the edge of the European continental shelf and exposed to the Atlantic Ocean, Ireland has an abundant wind resource which will be extensively exploited in order to meet emissions reductions commitments and reduce dependence on imported fossil fuels.

\section{THE ALL-ISLAND GRID STUDY [4]}

The Irish All-island Grid Study (AGS), jointly commissioned by the two governments, was a comprehensive assessment of the technical and economic implications of incorporating large amounts of variable, non-dispatchable renewable energy (principally wind) into the Irish system by the year 2020. Specialist consultants were commissioned to conduct studies (work streams - WS) in five areas: WS1: Resource Assessment, WS2a: Generation Portfolios, WS2b: Dispatch Study, WS3: Network Study and WS4: Cost Benefit Analysis. Six possible generation portfolios (P1-6) were examined (P6 was found to be impracticable). Further renewable generation included 274 to $428 \mathrm{MW}$ of base plant (comprised of landfill gas (68MW), biogas (73MW), biomass generation $(25-167 \mathrm{MW})$, biomass co-firing (104MW) and sewage gas (4-16MW)). Each portfolio included a complementary suite of thermal generation technologies including gas turbines (aero-derivative, combined and open cycle; ADGT, CCGT, OCGT), as well as coal-, peat-, oil- and gas-fired Rankine cycle plant. Thermal generation capacity comprised existing plant expected to still be operational in 2020 , along with various combinations of new gas turbine and coal units. This paper concentrates on the results of P5, which saw the maximum feasible penetration of renewable energy examined in the study $(6000 \mathrm{MW}$ wind, $508 \mathrm{MW}$ hydro/pumped storage, $360 \mathrm{MW}$ base renewables and $200 \mathrm{MW}$ tidal). In P5 renewable technologies accounted for $47 \%$ of total installed capacity, producing $42 \%$ of energy generated over the year. Key findings were that in comparison with a 'business as usual' scenario ( $\mathrm{P} 1,23 \%$ renewables capacity), this level of renewable generation would result in a $25 \%$ reduction in $\mathrm{CO}_{2}$ emissions. Security of supply would be enhanced, with a $25 \%$ reduction in fossil fuel imports overall and most notably a reduction on gas imports of $28 \%$. Ireland is heavily dependent on gas, which currently accounts for over $45 \%$ of electricity generation $[2,3]$. The total additional costs to achieve these reductions, including operational costs (fuel and $\mathrm{CO}_{2}$ emissions, based on a carbon price of $€ 30 /$ tonne), interconnector electricity imports, transmission network reinforcement costs and investment in renewable and conventional generation were only $€ 170 \mathrm{M} /$ annum (7\%) higher than the $€ 3,190 \mathrm{M} /$ annum required for $\mathrm{P} 1$.

TABLE I

AGS: VIABLE, NON-DISPATCHABLE RENEWABLE GENERATION CAPACITIES (VALUES IN MW)

\begin{tabular}{|c|c|c|c|c|c|}
\hline & \multicolumn{5}{|c|}{ Portfolio } \\
\cline { 2 - 6 } & 1 & 2 & 3 & 4 & 5 \\
\hline Tidal & 70 & 70 & 70 & 70 & 200 \\
\hline Wind & 2000 & 4000 & 4000 & 4000 & 6000 \\
\hline Total & 2070 & 4070 & 4070 & 4070 & 6200 \\
\hline
\end{tabular}


AGS was a ground-breaking study, innovative in its scale, incorporation of stochastic dispatch simulation in WS2B, and its minimization of network reinforcement requirements in WS3. It was a high-level analysis of the key aspects of the integration of large amounts of renewable generation into a small, relatively isolated, national power system. However, it also identified areas requiring further research, including technical issues such as increasingly flexible operational regimes for thermal units which currently function as highmerit/base load plant, and the economic implications of altered modes of operation for such units.

\section{THERMAL GENERATION IN IRELAND}

Total all-island generation capacity is currently 9932MW (all technologies), comprising $7666 \mathrm{MW}$ of thermal generation, $1569 \mathrm{MW}$ wind and $697 \mathrm{MW}$ of other renewables. Thermal capacity is made up as shown in Table II [2,3]:

TABLE II

COMPOSITION OF CURRENT THERMAL GENERATION CAPACITY (VALUES IN MW)

\begin{tabular}{|l|c|c|c|c|c|}
\hline Cycle & \multicolumn{3}{|c|}{ Rankine } & Brayton & Combined \\
\hline Fuel & Gas/HFO & Coal & Peat & Gas & Gas \\
\hline Capacity & 1852 & 1313 & 346 & 833 & 3322 \\
\hline
\end{tabular}

1594 MW of heavy fuel oil (HFO) and gas Rankine cycle generation capacity will be decommissioned by 2013, to be replaced by $863 \mathrm{MW}$ of combined cycle gas turbine (CCGT) generation. Of the extant base load and mid-merit plant, the units listed in Table III were assumed in AGS to still be operational in 2020.

\section{BASE LOAD AND CYCLIC OPERATION}

Large (>200MW) Rankine cycle steam-electric and CCGT generating units have previously been used as base load in the two Irish power systems, generally operating near maximum capacity in steady state conditions, with very few (typically<10) stop/start cycles per year [5], and annual capacity factors of around $80 \%$ [6].

Materials and components were selected to maximize unit lifespan on the basis of their ability to function within a restricted range of high temperature and pressure conditions; by definition, creep (deformation of material over time by high temperature and pressure) conditions [7].

Increased competition engendered by market liberalization, combined with the expanding capacity of variable generation from renewable sources and changes in system load, requires increasingly flexible, cyclic operation of thermal plant (in this paper cyclic operation includes low-load, load-following and on/off cycling, the latter comprising hot, warm and cold restarts, dependant on time offline).
TABLE III

EXTANT MID-MERIT AND BASELOAD PLANT, EXPECTED TO BE OPERATIONAL IN 2020 (VALUES IN MW)

\begin{tabular}{|c|c|c|c|c|}
\hline Unit ID & Capacity & Cycle & Fuel & Age(2008) \\
\hline AD1 & 258 & Rankine & Gas & 28 \\
\hline K1 & 236.6 & Rankine & Coal/Oil & 26 \\
\hline K2 & 236.6 & Rankine & Coal/Oil & 26 \\
\hline MP1 & 280 & Rankine & Coal & 23 \\
\hline MP2 & 280 & Rankine & Coal & 23 \\
\hline MP3 & 280 & Rankine & Coal & 23 \\
\hline PBC & 480 & CCGT & Gas & 9 \\
\hline ED1 & 117.6 & Rankine & Peat & 8 \\
\hline DBP & 415 & CCGT & Gas & 6 \\
\hline HNC & 343 & CCGT & Gas & 6 \\
\hline B31 & 251.6 & CCGT & Gas & 5 \\
\hline B32 & 251.6 & CCGT & Gas & 5 \\
\hline B10 & 102 & CCGT & Gas & 5 \\
\hline LR4 & 91 & Rankine & Peat & 4 \\
\hline CPS & 413 & CCGT & Gas & 3 \\
\hline WO4 & 137 & Rankine & Peat & 3 \\
\hline TY & 379 & CCGT & Gas & 2 \\
\hline HN2 & 412 & CCGT & Gas & 1 \\
\hline
\end{tabular}

This mode of operation causes major fluctuations in temperature and pressure, leading to fatigue stress, a significant departure from creep conditions.

The most common problem resulting from cycling base load units is thermal fatigue damage $[5,6,8,9]$. This can appear either as cracking or complete mechanical failure of components. Cracking is caused by excessive thermal gradients in steam-metal and through-wall temperatures associated with the rapid changes of condition seen during start-up, load changing and shut-down. It is most often seen in thick-walled components such as heat recovery steam generators (HRSG) or boiler superheater headers, where temperature changes cause joint deformation. Other effects include burst steam pipes, valve damage, coating failures and quenching damage due to condensate formation [9]. The damage caused by switching mode of operation and the incremental effects of cycling are not immediately obvious. Typically, it may take from three to seven years before covert damage becomes apparent. An increase in the failure rate of key components is evidenced by an increase in equivalent forced outage rate (EFOR) and reduction in unit availability (see Fig. 1) $[7,8,10]$. It should also be noted that the most damaging form of cycling by far is that caused by tripping [7], which is also likely to see an increase as component failure rates increase.

Creep and fatigue interact synergistically, leading to 
accelerated ageing and premature component failure. This interaction can drastically reduce the lifespan of typical power plant steel (2.25Cr1Mo), as shown in Fig. 2. Refs [7] and [11] found that although the effects of cycling are cumulative, i.e., damage increases with each unit load cycle, it is not the incremental impact of cycling that has the greatest effect on the ageing profile and premature decommissioning of a power plant, but rather the change from operating in one mode to another (i.e., from base load to cycling), combined with the number of years that a unit has operated as base load. In other words, the longer a unit has operated as base load, the more damage is incurred when it changes to cycling.

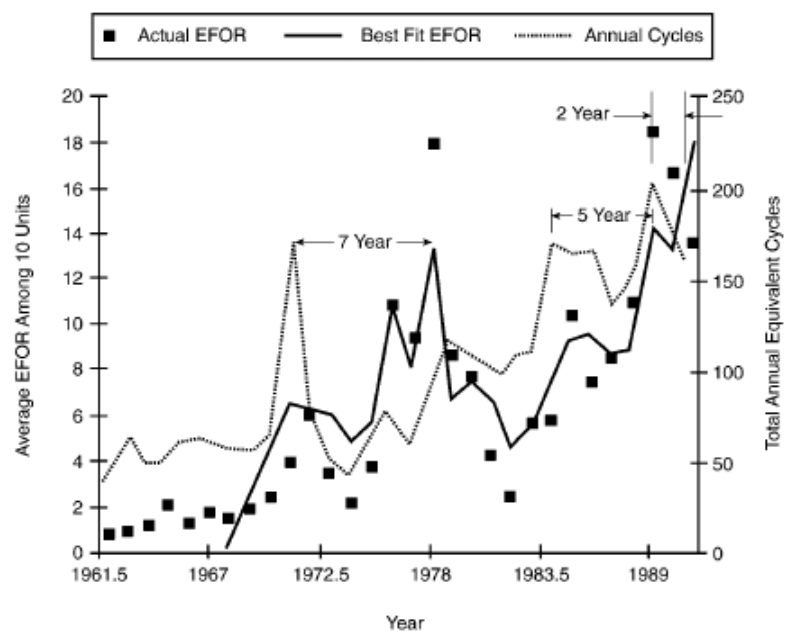

Fig. 1. Cycling/FOR Correlation. Note the delay between peak levels of cycling and peak EFOR [7]

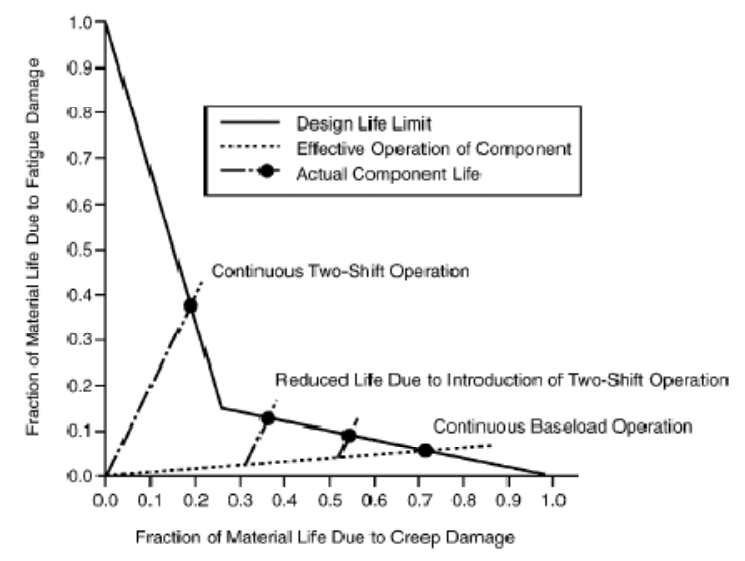

Fig. 2. Effect of creep/fatigue interaction on 2.25Cr1 Mo steel [7,9]

\section{OPERATIONAL MODES IN THE IRISH SYSTEM}

Since the start of the SEM, base load-designed units have seen increased competition for merit order ranking, resulting in increased two-shifting and load-following modes of operation, particularly for older and smaller units. Table IV compares the annual capacity factors (CF) of the fourteen large $(>200 \mathrm{MW})$ thermal units expected to be operational in 2020 , both for the first six months of the SEM using the PLEXOS [12] dispatch model (actual values normalized to annual values), and for 2020 as predicted in AGS. Although the dispatch models used in the SEM and AGS are different, they use the same plant characteristics dataset, and their results can be assessed to draw general conclusions. AGS used the WILMAR [13] (Wind Integration in Liberalized Electricity Markets) planning tool to stochastically model wind and wind-power generation forecast scenarios, system load, forced outages and reserve requirements for 2020. WILMAR was developed by the Risoe National Laboratory in Denmark and has been used to model the integration of large-scale wind power in Scandinavia and Germany. From the wind forecast scenarios, WILMAR generated a least cost scheduling model, which provided dispatch information for all thermal plant at hourly resolution. The time series data for P5, with $6 \mathrm{GW}$ of wind generation were analyzed by Ulster to establish the levels of cycling, low-load and load-following operation that conventional units were required to perform.

In the WILMAR 2020 dispatch model, coal units (K1 and 2; MP1, 2 and 3) saw an increase in CF, apparently moving towards base load operation, however a comparison of the number of starts required to achieve

TABLE IV

COMPARISON OF ANNUAL CAPACITY FACTORS FOR 2007/8 (ACTUAL) AND 2020 (PREDICTED)

\begin{tabular}{|c|c|c|c|}
\hline Unit ID & CF 2007/8 \% & CF 2020 \% & Change \% \\
\hline AD1 & 43.14 & 3.6 & -83.4 \\
\hline K1 & 52.9 & 64.3 & +21.6 \\
\hline K2 & 57.8 & 65.6 & +13.5 \\
\hline MP1 & 73.2 & 74.5 & +1.8 \\
\hline MP2 & 58.2 & 70.8 & +21.6 \\
\hline MP3 & 70.8 & 70.6 & -0.3 \\
\hline PBC & 73.1 & 40.9 & -44.0 \\
\hline DBP & 89.2 & 77.6 & -13.0 \\
\hline HNC & 69.1 & 50.4 & -27.1 \\
\hline B31 & 53.8 & 21.0 & -61 \\
\hline B32 & 64.8 & 20.9 & -67.7 \\
\hline CPS & 85.1 & 64.4 & -24.3 \\
\hline TY & 81.5 & 62.6 & -23.2 \\
\hline HN2 & 81.3 & 81.7 & 0.5 \\
\hline
\end{tabular}


this shows that K1 (111 starts) and K2 (106 starts) operated principally as mid-merit, two-shifting plant, while MP 1, 2 and 3 (11, 18 and 17 starts respectively) operated as near-base load (see section VII). AD1, the oldest unit on the system expected to be operational in 2020, also saw a dramatic change in operation from loadfollowing to peaking operation.

However, the greatest change in operation overall is seen in CCGT units. Figs 3 and 4 illustrate the increasingly flexible modes of operation demanded of CCGT plant in a high (6GW) wind penetration in comparison with today by plotting annual $\mathrm{CF}$ against total starts. Put simply, for most base load plant, more wind will mean operating outside design conditions, with more starts and lower CFs.

\section{CCGTs diversity of operation $2007 / 8$}

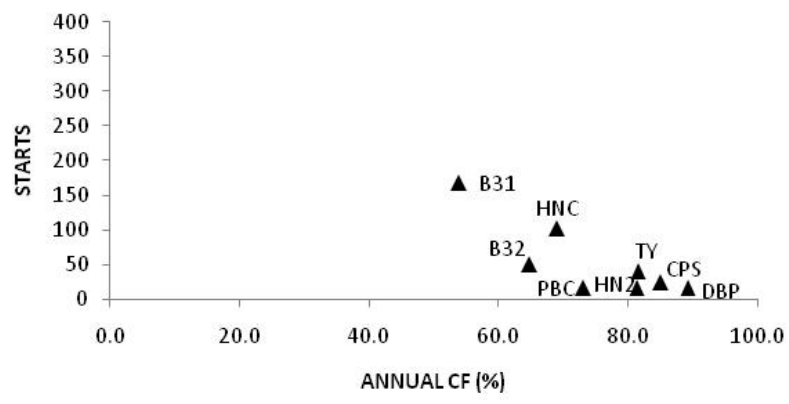

Fig. 3. Diversity of operational modes for CCGT units during the first 6 months of the SEM. Units clustered at the bottom right of the graph (PBC, HN2, TY, CPS and DBP) operated largely as base load (low starts, high CFs) during this period; $\mathrm{B} 31, \mathrm{~B} 32$ and $\mathrm{HNC}$ were required to operate more flexibly.

Based on SEM metered generation data supplied by the Northern Ireland Authority for Utility Regulation (NIAUR).

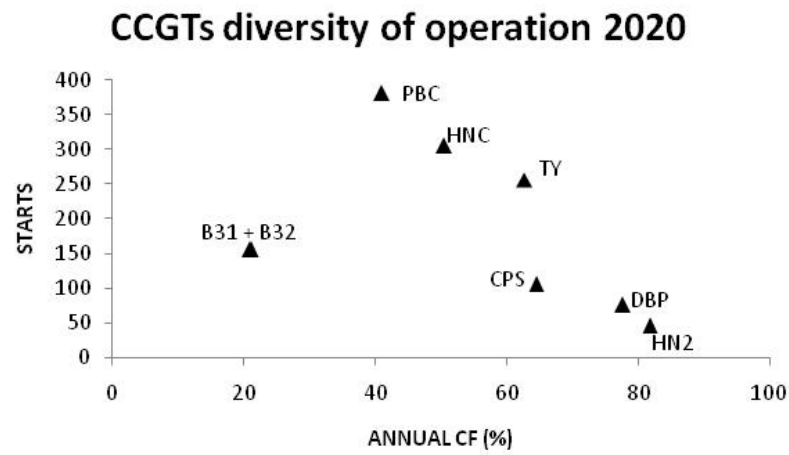

Fig. 4. Increased diversity of operational modes for CCGT units as predicted by WILMAR for 2020 , with $6 \mathrm{GW}$ of wind generation capacity. Notice that only HN2, DBP and possibly CPS could still be described as base load. Extensive two-shifting and even double two-shifting are required of $\mathrm{PBC}$, HNC and TY. B31 and B32 are primarily used for load-following and reserve. Based on AGS data supplied by Risoe National Laboratory with the permission of The Department of Enterprise, Trade and Investment (DETI).

\section{ESTIMATES OF CYCLING COSTS}

The principal cost effects of changing operational mode are seen in increases in capital expenditure for component replacement and maintenance costs, lower availability rates due to higher EFOR and outage time, prematurely degraded plant efficiency and higher heat rates [11]. Quantifying the degree to which individual units are affected by cycling is dependent on factors including generation technology, plant capacity, age, design, historical operation regimes and maintenance record [8].

Fuel and carbon costs are not included in any of the following estimates:

1) Ref [7] estimated costs for hot and cold starts over an extremely wide range of plant size and type; a hot start is estimated to cost between $€ 3,100$ for small units and up to $€ 70,000$ for very large units, while a cold start is estimated to cost anything from $€ 12,000$ to $€ 390,000$.

2) Ref [7] also produced average costs for a $1,000 \mathrm{MW}$ coal unit as follows:
a. Hot start - $€ 3,000$
b. Warm start - €3,400
c. Cold start - $€ 55,000$

3) Ref [11] estimated the range of costs for smaller coal units (148-280MW) at:
a. Hot start $-€ 5,400-€ 9,200$
b. Warm start - c. $€ 12,000$
c. Cold start $-€ 12,000-€ 16,000$

4) Research into costs for two-shifting CCGT units [9] based on increased manpower costs, heat rate deterioration, reduced availability, and modifications and maintenance, produced an estimated mean cost per cycle of c.€9,200 (All costs converted to $€$ May 2008 values).

Using the Ref [7] mean values for small coal units and the Ref [9] estimate for two-shifting CCGT, conservative estimates for B31 (CCGT) and K1 (coal) for start-up costs alone for 2020 would be greater than $€ 1$ Million each. Clearly these are very approximate figures, and should only be interpreted as broadly indicative, however, the implication is clear; whether through outages, repairs and replacement generation later; or modifications and other preventive action now, the cost of cycling base units is going to increase substantially.

\section{CONCLUSION}

The impact on the Irish all-island system of increasingly flexible operation for base plant is already being felt. In the six months since the beginning of the SEM, older and smaller units have generally seen dramatic increases in cyclic operation as a result of being placed lower in the merit order 
than larger, high-efficiency modern CCGT units. As mentioned in section $\mathrm{V}$, this means that older Rankine cycle units, which have operated in some cases for almost thirty years as base load are now changing to cyclic operation. The implications of this are serious. For example, K1 was commissioned in 1982 and assuming that it was designed to run for 40-50 years, it has operated principally in base load mode for approximately $0.52-0.625$ of its design life. Referral to the creep/fatigue interaction curve in Fig. 2 suggests that the change of operational mode due to the SEM and the expansion of variable renewable generation could result in a remaining lifespan of less than 0.1 of design life, or five years, for components fabricated from 2.25Cr1Mo steel.

Within the next few years all thermal plant, including large, new CCGT units will see increased cyclic operation, as a result of the expansion of wind power. Ireland currently has $1569 \mathrm{MW}$ of wind capacity connected [2,3] with a further 466MW due for connection. Applications for c. 1300MW are currently being considered, and beyond this, another tranche of c. $3,000 \mathrm{MW}$ is waiting to be processed. Although some of these applications will be refused, wind generation capacity of around $6 \mathrm{GW}$ by 2020 , as envisaged by AGS P5, seems likely. The fact that some CCGT units are already being cycled at today's comparatively low wind penetration level suggests over-reliance on this technology. However, from the investor's viewpoint, the market still appears to favour CCGT, as indicated by the upcoming commissioning of two new c.430MW, high-efficiency CCGT units in 2009 and 2010 .

In order to develop a grid which operates efficiently with large amounts of wind, system and market operators should create market signals to discourage further investment in base CCGT and encourage investment in plant designed for flexible operation. Furthermore, if current trends continue, the system's already heavy dependence on gas will increase. In order to increase fuel diversity system authorities should promote the development of flexible generation technologies powered by a wide range of fuels other than gas.

\section{ACKNOWLEDGMENT}

The authors thank Fred Frazer of DETI, Colin Broomfield of NIAUR and Peter Reibom of Risoe National Laboratory for providing the generation data used in the preparation of this paper.

\section{REFERENCES}

[1] SEMO website, http://allislandmarket.com/

[2] Eirgrid, Generation Adequacy Report 2008-2014, November 2007, available at www.eirgrid.com

[3] System Operator for Northern Ireland (SONI) Generation Seven Year Capacity Statement 2007-2013, December 2006, available at www.soni.ltd.uk

[4] Department of Communications, Energy and Natural Resources (DCENR); and Department of Enterprise, Trade and Investment (DETI), All-island Grid Study, 2008.

[5] Lefton, Besuner, Grimsrud and Kuntz, Experience in Cycling Cost Analysis of Power Plants in North America and Europe, Aptech Engineering Services Inc. Technical Report 133

[6] Baxter, Sanford, Smith and Szczepanski, Analysis of combined cycle operating patterns, Proceedings of The $8^{\text {th }}$ International Conference on Probabilistic Methods Applied to Power Systems, 2004

[7] Electric Power Research Institute (EPRI), Palo Alto, CA, 1001507, Damage to Power Plants Due to Cycling, : 2001.

[8] S. Lefton, Aptech Engineering Services Inc. A Methodology to Measure the Impact of Cyclic Operations and power Derations on Plant Life and Reliability, , Aptech Technical Report number 018.

[9] EPRI, Palo Alto, CA, 1004796, Cyclic operation of Combined Cycle Plants: Design, Maintenance, Reliability and Cost Impacts, 2004.

[10] Lefton, Besuner and Agan, The Real Cost Implications of On/Off Cycling Combined Cycle Power Plants, Aptech Engineering Services Inc, Technical Report 167, 2006

[11] EPRI, Palo Alto, CA, 1004412, Determining the Cost of Cycling and Varied Load Operations: Methodology

[12] Energy Exemplar, PLEXOS for Power Systems, available at www.energyexemplar.com

[13] Reibom, Barth, Norheim, Ravn and Sorensen, Wind Power Integration in a Liberalized Electricity Market, Final Technical Report, 2006. 